\title{
ESCRITAS DE VIDA COMO POSSIBILIDADE DE RESISTÊNCIA
}

\author{
Angela Guida ${ }^{1^{\star}}$ \\ Betinha Yadira Augusto Bidemy ${ }^{1^{* *}}$ \\ Daniel Almeida Machado ${ }^{1 * * *}$ \\ ${ }^{1}$ Universidade Federal do Mato Grosso do Sul, Campo Grande, MS, Brasil
}

\begin{abstract}
Resumo:
Busca-se, com este artigo, engendrar reflexões acerca da narrativa epistolar como uma categoria de escrita de vida, na qual hibridez e fluidez são características importantes para o que se pretende discutir aqui - possibilidades de escritas de vida agirem como potência de escritas coletivas e a amplitude da narrativa epistolar no campo das narrativas literárias. Assim, o objetivo central aqui é discutir escritas de vida que se deslocam da intimidade para a coletividade e se oferecem como uma política de resistência, de modo especial, para se pensar o feminismo interseccional e Letter to my daughter (2008), de Maya Angelou, configura-se como um significativo exemplo desse tipo de narrativa, conforme se demonstrará ao longo deste artigo.

Palavras-chave: Interseccionalidade; Carta; Escritas de vida; Resistência; feminismo
\end{abstract}

\section{LIFE WRITING AS A POSSIBILITY OF RESISTANCE}

Abstract:

The aim of this paper is to produce reflections about the epistolary narrative as a category of life writing, in which hybridity and fluidity are important characteristics for what we intend to discuss here - the possibilities of life writings acting as a power of collective writings and the breadth of

\footnotetext{
"Professora/pesquisadora na área de Teoria da Literatura (UFMS). Mestre em Teoria Literária (UFJF), doutora em Ciência da Literatura (UFRJ) e pós-doutora em Estudos Literários (UFMG). Atua como docente (mestrado e doutorado) no Programa de Pós-Graduação em Estudos de Linguagens e Educação Matemática (UFMS). Em suas pesquisas, prioriza as relações transdisciplinares, com ênfase em estudos de ecocrítica, alteridade feminina e animal. E-mail: angelaguida.ufms@gmail.com. Orcid https://orcid.org/0000-0002-8948-646X.

${ }^{* *}$ Mestre em Estudos de Linguagens [UFMS] e doutoranda em Estudos de Linguagens [UFMS]. Atua como docente em duas universidades da Guiné-Bissau: Amílcar de Castro e Universidade Lusófona Guiné-Bissau. Suas pesquisas privilegiam a escrita de si no processo de política identitária de autoras e personagens femininas africanas. E-mail: yadirabidemy@gmail.com. Orcid https://orcid.org/0000-0002-3341-8142.

${ }^{* * *}$ Mestrando em Estudos de Linguagens [UFMS] e pesquisador de produções literárias de autoria feminina. Possui artigos publicados em importantes revistas nacionais na área de estudos feministas. E-mail: danimachx22@gmail.com. Orcid https://orcid.org/0000-0002-8286-1212.
} 
the epistolary narrative in the area of literary narratives. Thus, the main objective of this article is to discuss life writings that move from intimacy to collectivity and offer themselves as a policy of resistance, in particular, to think about intersectional feminism, and Maya Angelou's Letter to my daughter (2008) appears as an important example of this type of narrative, as will be demonstrated throughout this article

Keywords: Intersectionality; letter; life writings; resistance; feminism 
É claro que estou sabendo da pouquíssima falta de inocência de uma carta Ana C

Você me relega ao passado, e pode mentir um tanto, pode me jogar na lama, como poeira, eu levanto.

Vem me ferir com palavras, O seu olhar me cortando, Vem me matar com teu ódio, Mas como o ar, eu levanto Maya Angelou

\section{Para início de conversa... \\ Ilha do Desterro, Brasil, 2021 \\ Caras leitoras e leitores,}

Apenas cartas - como uma forma de arte ou algo assim².

Elizabeth Bishop

Para surpresa (ou seria decepção?) de quem se dedica ao estudo de cartas, o mercado de bolsas de luxo ousou com uma linha do acessório denominada "mystery bags". A Sekrè se propõe criar bolsas misteriosas, cujo lema é: "Every woman needs a secret" ("Toda mulher precisa de um segredo"). O segredo prometido pela grife de luxo se dá por meio de cartas que vão da Rainha Vitória a Charles Dickens, que são recortadas e incrustadas nas bolsas, garantindo o segredo e a exclusividade por cifras milionárias. No caso de Dickens, a carta escolhida se refere à recusa de um convite para ministrar uma palestra. Segundo Sean O'Neill (2020), o curioso de tudo isso é que Dickens destruiu muito de suas correspondências, temendo que elas pudessem cair em mãos erradas e revelar a intimidade de pessoas públicas, que não deveriam ser expostas à curiosidade alheia. $\mathrm{O}$ apelativo slogan da marca joga com a relação que se encontra amparada na ideia de que cartas são, por excelência, escritas sigilosas, logo, as bolsas da Sekrè oferecem esse ar de mistério por meio das cartas-adornos, criando uma relação de similitude com o desejo de vasculhar a bolsa e a carta de alguém como relações que operam no mesmo campo semântico: descobrir o que se esconde na bolsa e na carta. Iniciamos nossas reflexões com esse episódio trivial, a fim de ilustrar o alcance e amplitude das missivas, sobretudo num tempo refratário ao abrigo desse tipo de escrita, pelo menos no que diz respeito à forma tradicional de composição de cartas, como sentar-se à mesa, tomado/a pelo desejo de entregar-se a um tem- 
po de escuta de si e começar a rascunhar no papel fragmentos de vida cotidiana, fragmentos de si endereçados a alguém especial ou mesmo para deixar se perder em algum fundo de gaveta. Com a chegada dos e-mails, as idas aos correios para postagem de cartas pessoais foram rareando, bem como a espera pela passagem do carteiro na ânsia de receber algumas linhas de vida escritas num velho papel de carta bordado. Será mesmo culpa dos e-mails? Quem sabe...

Historicamente, a divisão da literatura em gêneros literários, isto é, modos de categorizar um objeto que é de natureza escorregadia, remonta a Poética, de Aristóteles, datada do século IV a.C. A despeito de sua longínqua demarcação temporal, o texto do filósofo grego ainda é o ponto de partida para o estudo analítico do monumento literário, configurando-se como leitura obrigatória para os/as estudiosos e estudiosas das áreas de letras, linguagens, teoria literária e adjacências. No entanto, o confronto entre a poética aristotélica e a literatura tem suscitado intensas discussões sobre o que é ou não literário, ou, da existência de critérios de literariedade. De um lado, a Poética prescreve os gêneros épico, lírico e dramático como categorias por excelência que classificam o literário. Por outro lado, a própria literatura vem dando sinais do entrecruzamento de meios e suportes, estilos e modos de dizer, derrubando os muros que possam enquadrar a linguagem literária enquanto noção certa de classificação. Por conseguinte, a clássica forma de tripartição dos gêneros, proposta por Aristóteles, não comporta mais uma leitura do enquadramento, tendo em vista o embaralhamento de categorias que textos canônicos como Dom Quixote (1605), de Miguel de Cervantes, e Tristram Shandy (1759), de Laurence Sterne já apresentavam há alguns séculos, ou das renovações poéticas de T.S. Eliot, Walt Whitman, Emily Dickinson, Stéphane Mallarmé, Paul Verlaine, Rimbaud, nos séculos XIX e XX. O que dizer do século XXI?

Os exemplos citados, embora de suma importância como modo de pensar as constantes renovações em torno dessa estranha instituição chamada literatura, para lembrar uma expressão de Jacques Derrida (2014), centram-se, ainda, confortavelmente naquilo que hoje classificamos como literatura. Embora, à sua época, tenham causado seus escândalos, talvez hoje dificilmente não sejam colocados no imaginário comum como pertencentes à grande constelação dos textos literários existentes, quer sejam lidos ou não. Como ficam outros textos e outros tipos de escritas, a saber, daquelas ditas como não-ficcionais, portanto, a família rejeitada no jardim das grandes musas da literatura? Diários, memórias, (auto) biografias, relatos, cartas, bilhetes. Que espaço ocupam? Que terreno podem habitar? Ficção ou documento?

Contemporaneamente, aqui tomando a expressão justamente como marco temporal, percebe-se uma profusão e divulgação, no universo das publicações, de escritas centradas no eu, as "escritas de si", relembrando a expressão cunhada por Foucault. Dessas, chama-nos a atenção o interesse em cartas. John Kirkland, por exemplo, lança, em 2008, dois volumes que fazem parte da grande coletânea intitulada Love letters of great men, cartas românticas de nomes famosos como Beethoven, Fitzgerald, Mark Twain, Flaubert, Joyce, entre outros. No mesmo ano, a troca de correspondências entre Elizabeth Bishop e Robert Lowell é publicada 
em Words in Air: The Complete Correspondence Between Elizabeth Bishop and Robert Lowell. Em 2008, após um encontro com Paul Auster, J.M. Coetezee escreveu a ele propondo que trocassem correspondências. Por três anos, os escritores trocaram muitas cartas, nas quais além de trivialidades cotidianas, discutiram importantes questões ligadas à literatura de ambos e à literatura em geral. O resultado desses encontros epistolares foi o livro Here and now - letters 2008-2011. Em 2015, foi lançado o primeiro conjunto de cartas do volumoso espólio epistolar de Ernest Hemingway. Aliás, as cartas de Hemingway sempre foram objeto de desejo da curiosidade alheia, pois, muitas vezes, mal chegavam e seus parentes já as enviavam a revistas e jornais interessados em saber um pouco da intimidade do escritor americano.

Em 2017, os admiradores e admiradoras de Sylvia Plath puderam compreender muito da escrita soturna da poetisa americana por meio da publicação do primeiro volume de cartas do também extenso espólio epistolar de Sylvia - The Letters of Sylvia Plath volume 1: 1940-1956 e, em 2018, foram surpreendidos/as com a revelação de que Sylvia, um ícone do feminismo, fora vítima de violência doméstica em seu casamento com o poeta Ted Hughes. As revelações acerca desse relacionamento abusivo estão na publicação do segundo volume de cartas - The Letters of Sylvia Plath volume II: 1956-1963. Nas cartas trocadas com sua terapeuta, no período de setembro a outubro de 1962, Sylvia se queixa de ter sido agredida por Hughes em vários momentos, como é possível ver no fragmento de uma carta escrita em 22 de setembro de 1962. "Ted me bateu poucos dias antes do meu aborto. O bebê que eu perdi nasceria no dia do aniversário dele”. (PLATH, 2018, tradução nossa ${ }^{4}$ ).

O último texto em prosa que Oscar Wilde produziu foi justamente uma longa carta escrita no período em que passou na prisão. Uma carta pungente, na qual o escritor irlandês se desnuda por completo, revê suas relações, de modo especial, com Sir Alfred Douglas. "Estou completamente quebrado e sem casa, mas há coisas piores que isso no mundo. Sou muito franco quando digo que, em vez de sair desta prisão com meu coração cheio de amarguras contra o mundo, eu, de bom grado, de porta em porta, imploraria por meu próprio pão" (WILDE, 2001, p. 5, tradução nossa ${ }^{5}$ ). Na solidão da prisão, Wilde escreveu De profundis, carta de dor e de amor endereçada a seu amante Sir Alfred Douglas. Carta essa que, por muito tempo, foi motivo de disputa, uma vez que no marcador vocativo evidencia que a carta está endereçada a Sir Douglas, mas fora entregue ao amigo de Wilde, Robert Ross. Disputa judicial é outra questão que circunda o universo das cartas: a quem pertence uma carta? Ao remetente ou ao destinatário? Para Silviano Santiago, as cartas pertencem aos correios e, quando entregues, aos destinatários: "a carta pertence mais ao sistema dos correios, pertence mais ao destinatário do que ao signatário dela" (SANTIAGO, 2006, p. 235). Já a pesquisadora Eliane Vasconcellos atribui a esse pertencimento a ideia de direito autoral e direito material. "Do ponto de vista jurídico, o signatário detém o direito autoral da carta; o destinatário possui o direito material, ou seja, ele é dono do suporte, normalmente o papel em que a carta foi escrita" (VASCONCELLOS, 2008, p. 385). 
Escrita inicialmente para não ser publicada, a carta é o segredo que se desfaz, a confissão que se deixa ouvir, torna público o que deveria ser privado. Dissolvidas todas essas questões, tornamo-nos espécies de voyeurs, os intrusos que, participando de um rito para o qual não fomos convidados, descobrimos um pouco mais a respeito daqueles ou daquelas que lemos. Talvez isso explique o desejo por cartas no século XXI, que se confunde pelo desejo pela própria literatura. Não seriam desde sempre um só? O que revela o interesse pelas cartas de escritores ao redor do globo em pleno século XXI, época em que nos encontramos inundados pela facilidade de mensagens e caracteres nas redes sociais, a exemplo do Instagram, Twitter, Facebook. O que nos diz o interesse pelas cartas de escritores ao redor do mundo? Possuem alguma relação com suas próprias literaturas ou constituem um movimento a parte, para além do projeto literário? Há alguma relação entre o fazer epistolar e o exercício de escrita literária? Seriam as cartas, como certa vez disse a poetisa brasileira Ana Cristina Cesar, mais arrepiantes do que a própria literatura? "Depois da Emily Dickinson, estou em fase de Katherine Mansfield, leio tudo, inclusive biografias ordinárias (que leio arrepiada, I must confess que para dizer a verdade estou achando cartas e biografias mais arrepiantes que a literatura) e fico sonhando com essa personagem" (CESAR, 1999, 281).

As cartas, inegavelmente, em sua origem, são escritas de vida, escritas de si, no entanto, pensando na amplitude que abarca esse gênero, "um gênero que devorou todos os outros", neste artigo, vamos defender a ideia de uma escrita de vida que migra para uma escrita coletiva, a partir da obra Letter to my daughter, da escritora e ativista afro-americana Maya Angelou, a nosso ver, uma escrita de vida afrodiaspórica que se movimenta na direção do feminismo interseccional e se perfaz como política de resistência Nossa amplitude de leitura, entre outras, legitima-se nas palavras de Brigitte Diaz: "O estatuto genérico vago da carta abre para todos os horizontes epistemológicos. Porque zomba dos discursos constituídos, torna-se o instrumento ideal de um saber vivo. [...] Não se pode mais então falar verdadeiramente de gênero epistolar, por parecer que esse gênero devorou todos os outros" (DIAZ, 2016, p. 46, 50).

\section{O que nos dizem as cartas?}

Eu queria que as palavras [...]

atravessassem muros,

fizessem saltar fechaduras, abrissem janelas.

Michel Foucault

No decurso da historiografia literária, as cartas receberam um olhar desconfiado por parte de críticos de literatura, alegando se tratar de vida privada, intimidade demais, excesso de exposição do eu, logo, sem atrativos para análises literárias consistentes. Entretanto, essa leitura tem sido revista e muitos já consideram as epístolas como mais uma manifestação literária em prosa que traz frag- 
mentos de vida íntima que, ao contrário do que se acreditava, não diminuem em nada o valor literário do texto produzido. São narrativas literárias potentes que vêm mudando o cenário editorial. Há uma espécie de retomada e/ou redescoberta de uma estrutura narrativa bastante usada em tempos longínquos: o romance epistolar. Um dos exemplos mais antigos é o do livro Pamela: or, virtue rewarded, marco da literatura inglesa do século XVIII, escrito por Samuel Richardson. Ou mesmo no romance que não é estruturado de modo epistolar, a exemplo do belíssimo Orlando, de Virginia Woolf, há um curioso comentário que nos chama a atenção. De caráter (auto)biográfico, pois teria sido inspirado na amante de Virginia, Vita Sackville-West, foi descrito pelo próprio filho de Vita como "a carta de amor mais longa e elegante da literatura" (LORD, 2020, tradução nossa ${ }^{6}$ ). Aliás, não obstante a própria Virginia ser constantemente lembrada por sua carta de suicídio, escrita para seu marido Leonard Woolf, no dia 28 de março de 1941, seu entrecruzamento direto com as cartas se dá no absolutamente provocativo e atual ensaio Três Guinéus, escrito em 1938.

Em Três Guinéus, uma missivista assume o encargo de responder a dificílima pergunta de seu interlocutor - "como, em sua opinião, vamos evitar a guerra?" (WOOLF, 2019, p. 9) - sobre as possíveis maneiras para que a guerra fosse evitada e, em três cartas, oferece soluções para seu destinatário. Para cada solução encontrada, após longas provocações e debates consigo mesma, a personagem compromete-se a enviar um guinéu (moeda de ouro britânica) para ser aplicado em cada decisão e com isso agir na possível diminuição do expediente da guerra enquanto instrumento social necessário para se atingir determinados fins. Assumir o formato de cartas, que era um poderoso instrumento de comunicação no século passado, revela não só a inteligência de Woolf para utilizá-lo como estilo do livro, mas também, novamente, brinca com as possibilidades do gênero.

Em produções literárias mais contemporâneas, há escritores e escritoras que também fazem uso da estrutura de uma carta - marcação temporal, espacial, vocativo - a fim de produzir romances ou auto/biografias literárias, como é o caso de um dos mais promissores escritores da literatura americana atual, o americano-vietnamita Ocean Vuong e da veterana e poderosa voz em favor dos direitos civis dos negros e negras, a escritora afro-americana Maya Angelou. Em seu aclamado romance On Earth We're Briefly Gorgeous, Vuong (2019) nos apresenta um narrador-remetente que escreve uma longa carta para a mãe analfabeta, em que expõe, com doçura e crueza, problemas relacionados à raça, gênero e classe social, em que o bios do narrador-remetente, de origem vietnamita, homossexual e pobre, se entrelaça ao de Vuong, imigrante vietnamita que chegou aos Estados Unidos com apenas dois anos de idade, acompanhado da mãe iletrada. De certa forma, o texto de Vuong também se inscreve sob a rubrica de um texto diaspórico, uma vez que que ele fala/escreve de seu lugar de imigrante pobre e homossexual nos Estados Unidos. Sua escrita revela o deslocamento geográfico forçado e as consequências disso, como a discriminação, nada velada, com raízes em sua cor, raça e orientação sexual. Vuong produz um texto híbrido, fazendo uso de marcadores do gênero epistolar, como o vocativo de saudação inicial, o 
uso do pronome de segunda pessoa a fim de acentuar a presença do destinatário, isto é, o recurso fático, a trivialidade de assuntos como lembranças de idas ao supermercado, a unha lascada da mãe. O uso do "let me again" também sinaliza para o comportamento característico de quem escreve cartas, que são os vários recomeços de uma carta até sua escrita final. Quantos começos não se encontram amassados nas latas de lixo? Aliás, em uma entrevista concedida ao jornal El País (2020), Vuong justifica sua escolha pela forma epistolar, porque queria mais liberdade para digressão, o que, segundo ele, a estrutura de um romance tradicional não permitiria, sobretudo, nos Estados Unidos, onde há uma predileção pelo que é mais objetivo. "Escrevê-la como se fosse uma carta me permitiu usar a digressão, da qual a estética europeia é mais receptiva. Nos Estados Unidos, costuma-se ser mais direto. A novela epistolar é um espiral que nem sempre vai a um determinado lugar" (VOUNG, 2020, tradução nossa ${ }^{7}$ ).

Deixa eu começar de novo

Querida mãe,

Estou escrevendo para chegar até você - ainda que cada palavra que eu ponha no papel fique uma palavra mais longe de onde você está. Estou escrevendo para voltar ao tempo no ponto de parada na Virgínia, quando você olhou horrorizada um alce empalhado em cima da máquina de refrigerante, perto dos banheiros, a galhada fazendo sombra no teu rosto. No carro, você ainda sacudia a cabeça "Não entendo porque alguém ia fazer aquilo. Será que eles não vêem que aquilo é um cadáver? Um cadáver devia ir embora, não ficar preso para sempre daquele jeito (VUONG, 2021, p. $12^{8}$ ).

O contato, ou atravessamento, do universo epistolar no universo literário talvez possua como grande referente as missivas trocadas, nos anos de 1903 a 1908, entre o já consolidado poeta tcheco Rainer Maria Rilke e o aspirante a poeta e indeciso quanto a sua carreira militar Franz Kappus. Nas dez cartas, que até então nasciam da vontade de aconselhamento de Kappus e o desejo por algumas palavras de direcionamento do experiente Rilke, o público leitor se depara com uma comunicação que se confunde com a própria tessitura poética de Rilke e tornamse, lado a lado com sua poesia, uma força altamente literária para compreender a escrita do poeta. Outrossim, há reflexões sobre a própria obra de arte, a ciência, os contatos entre vida e literatura, ou mesmo o firmamento de que para ser escritor, tal qual todo trabalho, há de se ter um esforço árduo, pois o texto exige-o: “[...] penetre em si mesmo e procure a necessidade que o faz escrever. Observe se esta necessidade tem raízes nas profundezas do seu coração. Confesse à sua alma: 'Morreria, se não fosse permitido escrever?"' (RILKE, 2017, p. 78). Todavia, ainda sim encontram-se ali elementos que não fogem ao gênero carta, como o endereçamento, datação, as saudações e despedidas, o relato de momentos banais do cotidiano, como datas comemorativas ou outros eventos de descontração, acentuando o que estudiosos do gênero epistolar, como Brigitte Diaz, vêm dizendo: trata-se de hibridismo: "as cartas são textos híbridos e rebeldes a quaisquer identificações genéricas. Gênero literário indefinível, flutuam entre categorias vagas: arquivos, documentos, testemunhos" (DIAZ, 2016, p. 11) 
Movem-se, portanto, entre o não classificável em sua totalidade, isto é, ainda que de início sejam concebidas como "cartas", objetos em que um "eu" se endereça a um certo "outro", em que se há um propósito de comunicação, testando-se, inclusive, o canal fático, bem como o preenchimento de certos pré-requisitos, que podem ser cumpridos a rigor ou não, como as datas, a localização, entre outros, uma leitura do objeto carta em si pode revelar surpresas e impressões muito além do que se esperaria para aquilo que é considerado como epistolar, conforme veremos mais adiante com Letter to my daughter. A narração do banal e de eventos da realidade empírica mistura-se com proposições filosóficas, abstrações literárias, momentos que faz com que o leitor se questione: "isto deveria estar aqui?”. Ademais, faz-se necessário notar uma importante contribuição de Mikhail Bakhtin em seu Estética da criação verbal. Para Bakhtin, os gêneros são "tipos de enunciados estilísticos, temáticos e composicionais relativamente estáveis" (BAKHTIN, 2003, p. 266). O termo "relativamente" pressupõe aquilo que é incerto, que não pode ser definido de modo definitivo ou incontornável. Assim, mesmo que possamos traçar certas delimitações, como faz o próprio Bakhtin, a exemplo do "conteúdo temático, estilo e construção composicional" (BAKHTIN, 2003, p. 263), persiste o elemento instável, aquele espectro errante e movediço do gênero, totalmente aceitável, em que percebemos um movimento para além da classificação prescritiva do que aquele texto deveria ser ou tornar-se. Como já citado aqui por nós, "não se pode mais então falar verdadeiramente de gênero epistolar, por parecer que esse gênero devorou todos os outros" (DIAZ, 2016, p. 50). É nessa linha antropofágica de devoração (ou seria da ordem do inclassificável?) que passamos às discussões acerca da carta pluribiográfica e afrodiaspórica de Maya Angelou, em que sua escrita de vida de menina pobre do sul dos Estados Unidos, região notadamente marcada pelo racismo, desloca-se para escritas de vidas coletivas e, por conseguinte, escrita de resistência, afinal "quando escrevo eu, o significado é nós" (ANGELOU, 2018).

\section{O que nos diz a carta afrodiaspórica de Maya Angelou?}

Em 2008, nos Estados Unidos, chegava às livrarias Letter to my daughter, de Maya Angelou, um dos importantes nomes do ativismo negro e feminista. Quiçá uma das pioneiras na luta pelos direitos civis de negros e negras e do feminismo, dando os primeiros passos para o que seria uma das bandeiras defendidas pelo feminismo negro, que é a questão da interseccionalidade. Seu legado de luta individual-coletiva fez com que chamasse outras mulheres ora de filhas, ora de irmãs.

Querida filha,

Esta carta levou um tempo enorme para se formar. Durante todo esse tempo eu soube que queria lhe contar algumas lições que aprendi e em que condições as aprendi.

[...]

Eu dei à luz uma criança, um filho, mas tenho milhares de filhas. Vocês são negras e brancas, judias e muçulmanas, asiáticas, falantes de espanhol, 
nativas da América e das ilhas Aleutas. Vocês são gordas e magras, lindas e feias, gays e héteros, cultas e iletradas, e estou falando com todas vocês. Eis aqui minha oferenda (ANGELOU, 20199).

Em termos de estrutura narrativa, Letter to my daughter não se afina, por inteiro, com o gênero carta, pelo menos não dentro da estrutura tradicional, mas contém elementos que nos referenciam à ideia de carta, como a saudação inicial, o tom de intimidade e trivialidade com que narra os acontecimentos, fragmentos de poemas e letras de música como cúmplices da nossa escrita, os intermináveis "PS." No entanto, talvez, a maior indicação de que estamos diante de uma epístola esteja no próprio título, uma vez que a autora usa a denominação carta para nomear os 28 textos que compõem Letter to my daughter, num misto de carta e manifesto. Ainda nos é possível afirmar que, ao nomear seus textos como cartas, a autora estabelece um pacto com seus leitores e leitoras para narrar suas e, por que não dizer, nossas histórias e, desse modo, ainda que não estejamos diante de uma produção genuinamente epistolar, nos sentimos leitores e leitoras da grande carta de Angelou. Aliás, é até um pouco irônico usar a palavra "genuinamente" para se referir ao gênero epistolar, uma vez que o hibridismo é uma de suas principais características. Cada texto-carta é um endereçamento que permite a Maya Angelou olhar para sua história de mulher negra, o que faz com que desconfiemos de que a filha à qual Maya se refere possa também ser ela mesma. Por que não?

Conceição Evaristo, no prefácio que fez para a edição brasileira de 2019, destaca a potência da escrita de Angelou como uma voz individual-coletiva no que tange à luta das pessoas negras e, em especial, das mulheres. A potência dessa voz chega a ser uma ironia, pois Maya ficou 5 anos sem falar, uma consequência do estupro que sofreu na infância. Será que aquela criança assustada com a violência que sofrera e a emudecera poderia sequer sonhar que um dia sua voz ecoaria tão longe? "É a confissão de quem se comprometeu com as questões de seu tempo e dedicou a vida a empreender uma luta coletiva e pessoal, vencendo obstáculos particulares desde a infância, para se tornar protagonista da própria história" (EVARISTO, 2019). Mesmo se direcionando a todas as mulheres, Angelou f2alou de modo muito íntimo com as mulheres negras, uma vez que as confissões que ela faz ao longo de Letter to my daughter, bem como em outras obras de cunho auto/ pluribiográfico, são um espelho do que significa ser mulher negra e pobre, sobretudo, num país, por excelência racializado, como é o caso dos Estados Unidos, um país que durante muito tempo acreditou (ou ainda acredita?) na "submissão à ideia de que gente negra é inferior a gente branca, que eu raramente via" (ANGELOU, 2019 ${ }^{10}$ ), um país, em especial o sul, com experiência em reduzir "adultos negros a anões psicológicos", pois as crianças brancas pobres tinham permissão para se dirigir a negros mais altos e mais velhos pelo primeiro nome ou por qualquer outro nome que quisessem inventar" (ANGELOU, 2019 ${ }^{11}$ ). Assim, a escrita de Angelou também nos autoriza a pensar no feminismo interseccional, como vislumbramos, por exemplo, no fragmento do capítulo-endereçamento "Keep the faith", em que se recorda da força da avó negra, com quem passou boa parte da infância e que seguramente foi sua inspiração de luta e ativismo, deixando cla- 
ras lições à neta de que mulheres negras e pobres enfrentam realidades diferentes, afinal, "A Depressão, que tornou a sobrevivência difícil para todos, foi especialmente dura para uma mulher negra e solteira nos estados do Sul que sustentava um filho adulto inválido e criava dois netos pequenos" (ANGELOU, 2019 ${ }^{12}$ ), ou no poema de Mary Evans, que Angelou resgata no capítulo-endereçamento intitulado "Poetry".

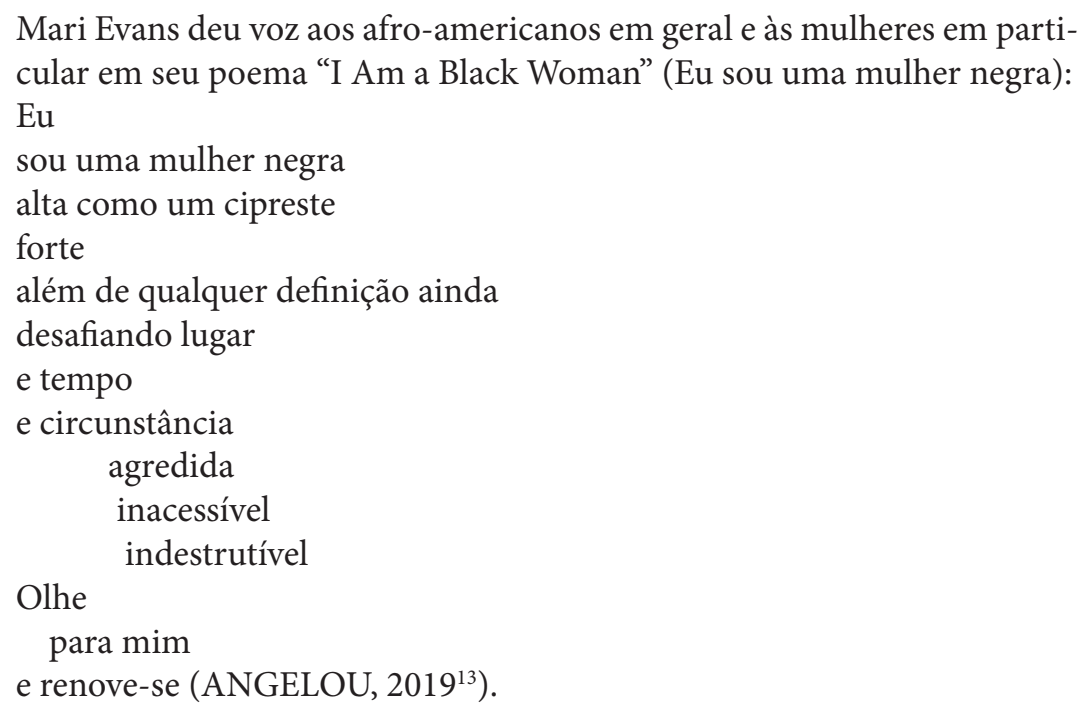

A interseccionalidade é uma das formas de se pensar de modo mais pluralizado questões que dizem respeito ao feminismo, haja vista ser tal conceito uma das chaves para incluir na pauta de discussões o debate acerca de mulheres pretas, pobres, lésbicas etc. bell hooks ${ }^{14}$ argumenta que: "A mulher branca pôde ao menos litigar por sua própria emancipação; as mulheres negras, duplamente escravizadas, não puderam mais do que sofrer e lutar e permanecer em silêncio" (HOOKS, 2020, p. 19). Mulheres negras, de forma geral, são marginalizadas pela cor da pele, e se forem pobres, lésbicas e periféricas, os estigmas são ainda piores. As mulheres brancas, por outro lado, embora também sejam vítimas de opressões do patriarcado, entre outras formas de opressão, são mais visíveis em sua luta em relação a outras raças e etnias. A noção de interseccionalidade, assim, surge para mapear as estruturas de poder que colocam as mulheres negras num lugar de invisibilidade, de apagamento da história, pois como bem diz Maya Angelou no famoso poema Still I rise, a grande narrativa tenta apagar as mulheres negras da história, criando uma narrativa colonial na qual o que se diz acerca das mulheres negras não condiz com suas lutas e, por isso, Angelou conclama as mulheres a se levantar, escrever e inscrever seus nomes na história: "Você pode me inscrever na história / Com suas mentiras amargas e distorcidas / Você pode me jogar na sujeira / Mas, ainda sim, como pó, eu levantarei” (ANGELOU, 1994, tradução nossa $\left.{ }^{15}\right)$.

Não sem alguma contestação, atribui-se à pesquisadora afro-americana Kimberlé Crenshaw a criação do termo interseccionalidade na década de 1980. No entanto, Crenshaw faz questão de lembrar a importância das discussões de 
outras feministas, como Angela Davis, por exemplo, para que fosse possível consolidar a teoria da interseccionalidade.

Muitos dos antecedentes para formar esse conceito são tão antigos quanto Anna Julia Cooper e Maria Stewart no século 19 dos Estados Unidos, e continuam seu caminho por meio de Angela Davis e Deborah King" .[...] Em cada geração, em cada esfera intelectual e até mesmo em cada momento político, existiram mulheres afro-americanas que se articularam a partir da necessidade de pensar e falar sobre raça através de uma lente que observe a questão de gênero, ou pensar e falar sobre feminismo através de uma lente que observe a questão de raça. Portanto, esse conceito é uma continuidade disso (CRENSHAW, 2014 ${ }^{16}$ ).

Crenshaw (2014) esclarece que o termo interseccionalidade surgiu no contexto em que foi necessário verificar a aplicação do feminismo negro em leis antidiscriminatórias no caso particular de um processo por discriminação de raça e gênero que cinco mulheres negras moveram contra a empresa General Motors. Segundo Crenshaw, foi preciso mostrar ao tribunal o que eles estavam se recusando a ver, isto é: que a discriminação de raça estava intrinsicamente atrelada ao gênero. No referido processo, comenta Crenshaw, alegou-se que nem todas as mulheres negras poderiam comprovar a discriminação por gênero, uma vez que nem todas haviam sofrido discriminação e, por outro lado, também não poderiam comprovar a discriminação por raça, levando em conta que nem todas as pessoas negras eram vítimas de discriminação, havendo, desse modo, a necessidade de fazer uso de um termo em que as noções de raça, gênero e classe social pudessem ficar evidentes. Ao ser questionada sobre o não ineditismo do conceito de interseccionalidade, levando em conta que raça e classe não são conceitos novos, Crenshaw argumenta que:

Classe não é um conceito novo e raça também não é novo. Porém, continuamos a debater e falar sobre esses assuntos, então, o que há de tão incomum no fato da interseccionalidade não ser um conceito novo? Por esse motivo não deveria haver razões para falar sobre isso? A interseccionalidade chama a atenção para invisibilidades que existem no feminismo, na luta contra o racismo, nas políticas de classe, então, obviamente é preciso muito trabalho, já que somos constantemente desafiados para estar atentos aos aspectos do poder que não fazem parte de nossas experiências pessoais (CRENSHAW, 2014 ${ }^{17}$ ).

Os movimentos para a libertação das mulheres negras são plurais, pois há racismo ao mesmo tempo em que há preconceito de gênero e de classe social para mulheres pobres ou habitantes de periferias. Diferentes elementos da sociedade patriarcal, como a religião, a colonização e a hierarquização da cor da pele privaram as mulheres pretas de direitos humanos básicos. O conceito de interseccionalidade, portanto, busca verificar outras especificidades que atravessam a existência dos negros. No caso da raça negra é preciso ter claro o fato de que o 
tratamento para um homem preto é diferente daquele que uma mulher preta recebe. A interseccionalidade está exatamente nesse fato de que há particularidades que devem ser levadas em consideração. A reivindicação de feminismos negros baseados na interseccionalidade é para que mulheres pretas possam se representar. Historicamente, o feminismo branco racializou os feminismos, hierarquizando, ou melhor, concebendo apenas uma forma de luta: a luta branca para mulheres brancas. A interseccionalidade não só evidencia os fenômenos de práticas racistas diferenciadas como é uma oportunidade, uma potência para desativar a hierarquização que oprime as mulheres pretas. Desse modo, a interseccionalidade surge como chave de leitura de textos importantes para o feminismo negro, como é o caso de Maya Angelou, bem como potência de voz para colocar em pauta políticas públicas que tirem da invisibilidade o feminismo de mulheres pretas que, no decurso da história, tiveram suas narrativas rasuradas e/ou apagadas. Maya Angelou é uma das responsáveis por fazer com que se esmoreça a ideia de que só há um lado da história a ser narrado e confidenciado. Com suas narrativas duras, mas ao mesmo tempo ternas, Angelou colocou o dedo na ferida aberta em corpos negros, sobretudo, femininos. Assim, voltamos à questão: o que nos diz a carta diaspórica de Maya Angelou?

Se é mesmo que o gênero carta devora todos os outros gêneros, como afirma Brigitte Diaz, talvez ainda seja cedo para afirmar, no entanto, uma coisa é certa: a liberdade para escritas de vida que as cartas permitem é incontestável, como Vuong assinalou. Escrever assinando com a rubrica de uma carta, decerto permite mais liberdade não só a quem escreve, mas também a quem se destina, que, por sua vez, se sente mais íntimo, mais próximo do escritor-remetente. No caso da escrita de Maya Angelou, a amplitude é ainda muito maior, posto que a autora faz uso da sua escrita de vida, da sua escrita íntima quando, na verdade, esta escrita de si é um chamado para a produção de uma escrita coletiva de resistência ao patriarcado, ao racismo estrutural, bem como a todas e quaisquer estruturas de poder que tentam colonizar e apagar as escritas de vidas daqueles que não se encontram do lado das narrativas hegemônicas. Resistência e sobrevivência como tão bem nos dizem os versos que compõem Letter to my daughter, versos de uma escrita de si que se abrem a todas as formas de alteridade e nos chamam à luta por dias melhores, porque apesar dos pesares amanhã há de ser outro dia...

Onde os ventos do desapontamento levaram ao chão a casa dos meus sonhos e a raiva, como um polvo, enrolou seus tentáculos em minha alma eu parei. Parei em minhas pegadas e procurei uma coisa que pudesse me curar (ANGELOU, 2019 ${ }^{18}$.

Saudações, Angela, Betinha, Daniel

PS: Quando escrevo eu, o significado é nós. Maya Angelou 
Notas

1. No original: "You may write me down in history/ With your bitter, twisted lies,/ You may trod me in the very dirt/ But still, like dust, I'll rise./ [...] You may shoot me with your words, / You may cut me with your eyes,/ You may kill me with your hatefulness,/ But still, like air, I'll rise". Tradução de Jorge Pontual.

2. No original: "Just letters - as an art form or something" (BISHOP, 1971). Tradução nossa.

3. https://www.sekrebag.com/en/handbag-editions-2/\#dickens

4. No original: "Ted beat me up physically a couple of days before my miscarriage: the baby I lost was due to be born on his birthday" (PLATH, 2018, p. 72).

5. No original: "I am completely penniless, and absolutely homeless. Yet there are worse things in the world than that. I am quite candid when I say that rather than go out from this prison with bitterness in my heart against the world, I would gladly and readily beg my bread from door to door" (WILDE, 2001, p. 5).

6. No original: "The longest and most charming love letter in literature".

7. No original: "Escribirla como si fuera una carta me permitió usar la digresión, a la que la estética europea es más receptiva. En Estados Unidos, se suele ir más al grano. La novela epistolar es una espiral que no siempre va a un lugar determinado" (VUONG, 2020).

8. No original: "Let me again

Dear ma,

What I am about to tell you you will never know. But so be it. I am writing to reach you - even if each word I put down is one word further from where you are. I am writing to go back to the time, at the rest stop in Virginia, when you stared, horror-struck, at the taxidermy buck hung over the soda machine by the restrooms, its antlers shadowing your face. In the car, you kept shaking your head. "I don't understand why they would do that. Can't they see it's a corpse? A corpse should go away, not get stuck forever like that" (VUONG, 2019, p. 12).

9. No original: "Dear Daughter,

This letter has taken an extraordinary time getting itself together. I have all along known that I wanted to tell you directly of some lessons I have learned and under what conditions I have learned them.

$[\ldots]$

I gave birth to one child, a son, but I have thousands of daughters. You are Black and White, Jewish and Muslim, Asian, Spanish-speaking, Native American and Aleut. You are fat and thin and pretty and plain, gay and straight, educated and unlettered, and I am speaking to you all" (ANGELOU, 2008, p. 16-17). Tradução de Celina Portocarrero.

10. No original: "submission to the idea that black people were inferior to white people, who I saw rarely"(ANGELOU, 2008, p. 42). Tradução de Celina PortocarNo original: "demoting even large adult blacks to psychological dwarfs. Poor white children had the license to address lauded and older blacks by their first names or by any names they could create" (ANGELOU, 2008, p.43). Tradução de Celina Portocarrero.

11. No original: "The Depression, which was difficult for everyone to survive, was especially so for a single black woman in the Southern states tending her crippled adult son and raising two small grandchildren" (ANGELOU, 2008, p. 100). Tradução de Celina Portocarrero. 
12. No original: "I/ am a black woman/tall as a cypress/Strong/ beyond all definition still/defying place/and time/and circumstance/ assailed/impervious/indestructible/ Look/ on me and be/ renewed" (ANGELOU, 2008, p. 105). Tradução de Celina Portocarrero.

13. Em suas obras, a autora faz uso apenas de letras minúsculas para grafar seu nome. Justifica essa opção, alegando que o que diz é mais importante do que a pessoa dela. Respeitamos a decisão da autora e por isso grafamos seu nome com letras minúsculas, no entanto, não concordamos com sua justificativa. A pessoa que fala é tão importante quanto o conteúdo de sua fala.

14. No original: "You may write me down in history /With your bitter, twisted lies, / You may trod me in the very dirt/But still, like dust, I'll rise"” (ANGELOU, 1994, p. 240).

15. No original: "So many of the antecedents to it are as old as Anna Julia Cooper, and Maria Stewart in the 19th century in the US, all the way through Angela Davis and Deborah King [...]. In every generation and in every intellectual sphere and in every political moment, there have been African American women who have articulated the need to think and talk about race through a lens that looks at gender, or think and talk about feminism through a lens that looks at race. So this is in continuity with that". Tradução de Geledés.

16. No original: "Class is not new and race is not new. And we still continue to contest and talk about it, so what's so unusual about intersectionality not being new and therefore that's not a reason to talk about it? Intersectionality draws attention to invisibilities that exist in feminism, in anti-racism, in class politics, so obviously it takes a lot of work to consistently challenge ourselves to be attentive to aspects of power that we don't ourselves experience". Tradução de Geledés.

17. No original: "Where the winds of disappointment/ dash my dream house to the ground/ and anger, octopus-like, wraps its tentacles/ around my soul/ just stop myself. I stop in my tracks/ and look for one thing that can/ heal me" (ANGELOU, 2008, p. 111). Tradução de Celina Portocarrero.

\section{Referências}

ANGELOU, Maya. The complete collected poems of Maya Angelou. New York: Random House, 1994.

ANGELOU, Maya. Letter to my daughter. New York: Random House, 2008.

ANGELOU, Maya. In: Maya Angelou tem primeira e última autobiografias publicadas no brasil. Revista Cult. 27 de Fevereiro de 2018. Disponível em: https://revistacult. uol.com.br/home/maya-angelou-autobiografias. Acesso em 04 nov. 2020.

ANGELOU, Maya. Carta a minha filha [recurso eletrônico]. Tradução de Celina Portocarrero. 2. ed. Rio de Janeiro: Agir, 2019.

BAKHTIN, Mikhail. Estética da criação verbal. Tradução de Paulo Bezerra. 4. ed. São Paulo: Martins Fontes, 2003.

CESAR, Ana Cristina. Correspondência incompleta. FREITAS FILHO, Armando; HOLLANDA, Heloisa Buarque de (orgs). Rio de Janeiro: Aeroplano, 1999.

CRENSHAW, Kimberlé. In: Kimberlé Crenshaw sobre interseccionalidade: Eu queria criar uma metáfora cotidiana que qualquer pessoa pudesse usar. Geledés. 27 de Setembro de 2014. Disponível em: https://www.geledes.org.br/kimberlecrenshaw-sobre-intersecionalidade-eu-queria-criar-uma-metafora-cotidianaque-qualquer-pessoa-pudesse-usar/. Acesso em 29 mar. 2021.

DERRIDA, Jacques. Essa estranha instituição chamada literatura. Tradução de Marileide Dias Esqueda. Belo Horizonte: Editora UFMG, 2014. 
DIAZ, Brigitte. O gênero epistolar ou o pensamento nômade: formas e funções da correspondência em alguns percursos de escritores no século XIX. Tradução de Sandra Ferreira. São Paulo: EDUSP, 2016.

EVARISTO, Conceição. Convocação à ternura. In: Carta a minha filha. Tradução de Celina Portocarrero. Rio de Janeiro: Agir, 2019.

HOOKS, bell. E eu não sou uma mulher?: mulheres negras e feminismo. Tradução de Bhuvi Libanio. 4. ed. Rio de Janeiro: Rosa dos Tempos, 2020

LORD, Annie. In: The indy book club: Virginia Woolf's lesbian love letter Orlando joyfully deconstructs the gender binary. Independent. 01 de julho de 2020. Disponível em: https://www.independent.co.uk/arts-entertainment/books/ features/indy-book-club-virginia-woolf-orlando-lesbian-love-letter-genderlgbt-a9593041.html. Acesso em 20 nov. 2020.

O'NEIL, Sean. In: Dickens legacy cannibalised for fashion. The Times. 22 de Fevereiro de 2020. Disponível em: https://www.thetimes.co.uk/article/dickens-legacycannibalised-for-fashion-bx7w90j86> Acesso em 12 nov. 2020.

PLATH, Sylvia. The Letters Plath vol II: 1956-1963. New York: Harper, 2018.

RILKE, Rainer. Maria. Poemas e cartas a um jovem poeta. Tradução de Geir Campos e Fernando Jorge. Rio de Janeiro: Nova Fronteira, 2017.

SANTIAGO, Silviano. Destinos de uma carta. In: Ora (direis) puxar conversa!. Belo Horizonte: Editora UFMG, 2006. p. 229-246.

VASCONCELLOS, Eliane. Intimidade das confidências. Revista Teresa, São Paulo, n. 8/9, 2008. Disponível em: http://www.revistas.usp.br/teresa/article/view/116762. Acesso em 19 nov. 2020.

VUONG, Ocean. On Earth We're Briefly Gorgeous. New York: Penguin, 2019.

VUONG, Ocean. In: La carta a su madre analfabeta de un hijo de la Guerra de Vietnam: El escritor Ocean Vuong, última revelación de las letras estadounidenses, escribe desde su experiencia como joven inmigrante gay. El País. 16 de maio de 2020. Disponível em: https:/elpais.com/cultura/2020-05-16/la-carta-a-su-madreanalfabeta-de-un-hijo-de-la-guerra-de-vietnam.html. Acesso em 04 nov. 2020.

VUONG, Ocean. Sobre a Terra somos belos por um instante. Tradução de Rogério W. Galindo. Rio de Janeiro: Rocco, 2021.

WILDE, Oscar. De profundis. Phoenix Edition. 2001. Disponível em: http://www. dominiopublico.gov.br/download/texto/ph000457.pdf. Acesso em 30 out. 2020.

WOOLF, Virginia. Três guinéus. Tradução de Tomaz Tadeu. Belo Horizonte: Autêntica Editora, 2019.

Recebido em: 30/11/2020

Aceito em: 16/03/2021 